\title{
Evolução da qualidade microbiológica e físico-química do leite pasteurizado
} Evolution of microbiological and physico-chemical quality of pasteurized milk

\author{
Natalia Gonzaga ${ }^{1}$; Gabriela Casarotto Daniel ${ }^{1}$; Juliana Mareze1; Louise Rodrigues \\ Mariano Marioto ${ }^{1}$; Ronaldo Tamanini' ${ }^{2}$; Vanerli Beloti ${ }^{3}$
}

\begin{abstract}
Resumo
A qualidade do leite é definida, entre outros parâmetros, por um reduzido número de micro-organismos deteriorantes, baixa contagem de células somáticas e ausência de patógenos e resíduos químicos. Diversos trabalhos realizados em diferentes regiões do país têm enfatizado o elevado percentual de amostras fora dos padrões. O objetivo do presente trabalho foi avaliar a evolução da qualidade microbiológica e físicoquímica do leite pasteurizado produzido no Estado do Paraná ao longo de 7 anos. Foram analisadas 457 amostras de leite Pasteurizado, sendo 104 amostras no ano de 2008, 269 amostras em 2011 e 84 amostras em 2014. As amostras foram submetidas às análises físico-químicas de crioscopia e pesquisa de enzimas fosfatase alcalina e peroxidase. Quanto às análises microbiológicas, foram realizadas contagens de coliformes a $30^{\circ} \mathrm{C}$, coliformes $45^{\circ} \mathrm{C}$ e contagem padrão em placas. No laboratório, as análises físicoquímicas foram realizadas de acordo com a Instrução Normativa 68 e microbiológicas conforme a Instrução Normativa 62, ambas do Ministério da Agricultura Pecuária e Abastecimento. Os resultados demonstraram que com o passar dos anos a qualidade microbiológica do leite diminuiu, havendo um aumento de amostras fora do padrão. Quanto às enzimas fosfatase alcalina e peroxidase, a temperatura de pasteurização foi respeitada ao longo do tempo e o superaquecimento do leite foi mais frequente em 2011. As fraudes por adição de água diminuíram ou então ficaram mais sofisticadas, dificultando sua detecção.
\end{abstract}

Palavras-chave: Aeróbios mesófilos. Coliformes. Crioscopia. Peroxidase.

\begin{abstract}
Milk quality is defined, among other parameters, by a reduced number of spoilage microorganisms, low somatic cell count and the absence of pathogens and chemical waste. Several studies conducted in different regions of the country have emphasized the high percentage of samples not complying with the standard. The purpose of this study was to evaluate the evolution of microbiological and physicochemical quality of pasteurized milk produced in the State of Paraná over 7 years. A total of 457 samples of pasteurized milk were analyzed, 104 samples in 2008, 269 samples in 2011 and 84 samples in 2014. The samples were subjected to physicochemical analysis of cryoscopy and enzyme search for alkaline phosphatase and peroxidase. Regarding microbiological tests, coliform counts were performed at $30^{\circ} \mathrm{C}$ and $45^{\circ} \mathrm{C}$ and count plate pattern. In the laboratory, physicochemical analysis were performed according to the Normative 68 and microbiological as normative instruction 62, both of the Brazilian Ministry of Agriculture,
\end{abstract}

\footnotetext{
${ }^{1}$ Médica Veterinária. Residente em Inspeção de Produtos de Origem Animal - Leite e Derivados da Universidade Estadual de Londrina, Londrina, PR, Brasil.

${ }^{2}$ Médico Veterinário. Doutor em Ciência Animal, Laboratório de Inspeção de Produtos de Origem Animal (LIPOA) da Universidade Estadual de Londrina, Londrina, PR, Brasil. E-mail: ronaldo.tamanini@gmail.com

${ }^{3}$ Médica Veterinária, Pós-Doutora em Ciência Animal, Professora do Departamento de Medicina Veterinária Preventiva da Universidade Estadual de Londrina, Londrina, PR, Brasil. E-mail: vbeloti@uel.br
} 
Livestock and Food Supply. The results showed that over the years the microbiological quality of milk decreased, with an increase of non-standard samples. For enzymes alkaline phosphatase, peroxidase, the pasteurization temperature has been observed over time and the overheating of the milk was more frequent in 2011. Fraud by addition of water in milk has either decreased or become more sophisticated, making its detection difficult.

Keywods: Aerobic mesophilic. Coliforms. Cryoscopy. Peroxidase.

\section{Introdução}

O Brasil detém o segundo maior rebanho bovino do mundo, com cerca de 200 milhões de cabeças, sendo um dos principais segmentos do agronegócio brasileiro (FLORIÃO, 2013). Para fins comerciais o rebanho leiteiro brasileiro é o maior do mundo, embora a produtividade seja baixa, com média menor do que $5 \mathrm{~L} / \mathrm{vaca} / \mathrm{dia}$, e os problemas com a qualidade físico-química e microbiológica sejam frequentes (KOEHLER, 2000).

O Paraná é tradicionalmente um estado produtor de leite. A bovinocultura de leite iniciou-se como herança da colonização europeia que se firmou no estado, consolidado pela estrutura fundiária, onde a prevalência de pequenas propriedades é marcante. Em 10 anos, de 1996 a 2006, enquanto a produção de leite no Brasil passou de 18,5 bilhões de litros para 25,4 bilhões, crescendo $37,3 \%$, a produção do Paraná aumentou de 1,5 bilhões de litros para 2,7 bilhões, um crescimento de 78\% (VOLPI; DIGIOVANI, 2008).

Merece destaque a produção verificada nas regiões oeste e sudoeste do estado, que, somadas, correspondem a 49\% da produção do Paraná. Em 2006 os três municípios que apresentaram os maiores volumes de produção de leite no país localizam-se no Paraná: Castro, Marechal Cândido Rondon e Toledo, cujas produções somadas atingem 340,8 milhões de litros de leite, total equivalente à produção do estado do Maranhão (VOLPI; DIGIOVANI, 2008).

Alves (2001 apud CUNHA, 2007) descreve que a qualidade do leite é definida, entre outros parâmetros, por um reduzido número de microorganismos deteriorantes, baixa contagem de células somáticas e ausência de patógenos e resíduos químicos variados.

A contaminação do leite ocorre durante a ordenha e principalmente por contato com equipamentos, transporte, processamento e armazenamento (FRANCO; LANDGRAF, 2008).

Craven e Macauley (1983 apud CUNHA, 2007), afirmam que a carga microbiológica do leite in natura é de extrema importância na qualidade final de produtos lácteos. O leite de baixa qualidade microbiológica não se conserva por longos períodos, mesmo sob refrigeração, e não permite a produção de derivados nobres.

Em 2002 entrou em vigor a Instrução Normativa 51, que norteou a proposta do Plano Nacional de Melhoria da Qualidade do Leite. O principal foco desse plano foi a melhoria da qualidade do leite, estabelecendo parâmetros importantes como contagem de bactérias e padrões para contagem de células somáticas progressivamente mais severos até 2011. Em 2011 foi substituída pela Instrução Normativa 62. Ambas Instruções Normativas tinham como objetivo adequar esses parâmetros aos praticados no exterior, que são até $100.000 \mathrm{UFC} / \mathrm{mL}$ e $400.000 \mathrm{CCS} / \mathrm{mL}$ de leite (BRASIL, 2011). A melhoria da qualidade do leite proporciona maior vida útil do produto, melhor qualidade dos seus derivados e melhores características sensoriais.

Apesar da determinação legal, diversos trabalhos realizados com leite pasteurizado em diferentes regiões do país têm enfatizado o 
elevado percentual de amostras fora dos padrões microbiológicos e físico-químicos estabelecidos pela legislação em vigor ao longo do tempo (GIOMBELLI et al., 2011; SILVA et al., 2008).

Este trabalho teve por objetivo avaliar a evolução da qualidade microbiológica e físico-química do leite pasteurizado produzido no Estado do Paraná ao longo de 7 anos, relacionando-os aos padrões legais e verificando os impactos das legislações na melhoria da qualidade e verificando como as novas legislações influenciaram a qualidade do leite.

\section{Material e Métodos}

\section{Amostras}

As amostras foram recebidas no Laboratório de Inspeção de Produtos de Origem Animal LIPOA, pertencente ao Centro Mesorregional de Excelência em Tecnologia do Leite (CMETL) localizado na Universidade Estadual de Londrina (UEL), foram selecionadas amostras de tipos equivalentes de leite Pasteurizado, analisadas durante os anos de 2008, 2011 e primeiro semestre de 2014, isto é, em intervalos de 3 anos.

Foram analisadas 457 amostras de leite Pasteurizado, sendo 104 amostras no ano de 2008, 269 amostras em 2011 e 84 amostras em 2014, enviadas ao laboratório em suas embalagens originais de polietileno, acondicionadas em caixas isotérmicas, provenientes de 18 laticínios da região norte do Paraná. As amostras somente eram recebidas com temperatura inferior à $10^{\circ} \mathrm{C}$, não congeladas e sempre dentro do prazo de validade.

\section{Análises Físico-Químicas}

As amostras foram submetidas às análises físico-químicas de crioscopia e pesquisa de enzimas fosfatase alcalina e peroxidase, para avaliar se houve fraude por adição de água, ineficiência na pasteurização ou superaquecimento, respectivamente.

No laboratório, as análises físico-químicas foram realizadas de acordo com a Instrução Normativa 68 (BRASIL, 2006). Os padrões físico-químicos também coincidem entre a IN 51 e IN 62, exceto a crioscopia.

Para a crioscopia considerou-se como normal amostras que apresentaram resultados entre $-0,530$ a $-0,550$, de acordo com a IN 62, isso porque tanto amostras com mais de $-0,530^{\circ} \mathrm{H}$ como com menos de $-0,550^{\circ} \mathrm{H}$ podem ser passiveis de fraude, embora a IN 51 determinasse apenas o valor máximo de $-0,530$. A determinação do Índice Crioscópico foi efetuada utilizando três alíquotas contendo $2,5 \mathrm{~mL}$, em crioscopio eletrônico (PZL 7000). Para os testes de fosfatase alcalina e peroxidase em leite pasteurizado, os resultados devem ser negativo e positivo, respectivamente. Para a pesquisa de fosfatase alcalina utilizou-se um teste colorimétrico (Bioclin $\left.{ }^{\circledR}\right)$, realizado seguindo a orientação do fabricante.

\section{Análises Microbiológicas}

Quanto às análises microbiológicas, foram realizadas contagens de coliformes a $30^{\circ} \mathrm{C}$, coliformes $45^{\circ} \mathrm{C}$ e contagem padrão em placas, conforme a Instrução Normativa 62 (BRASIL, 2003). Os resultados obtidos foram comparados ao padrão determinado pela Instrução Normativa 51 (BRASIL, 2002), para amostra representativa de leite pasteurizado, que coincide com a determinação da Instrução Normativa 62 (BRASIL, 2011): contagem padrão em placas poderia estar até $80.000 \mathrm{UFC} / \mathrm{mL}$, coliformes a $30^{\circ} \mathrm{C}$ até $4 \mathrm{NMP} / \mathrm{mL}$ e coliformes a $45^{\circ} \mathrm{C}$ até 2 $\mathrm{NMP} / \mathrm{mL}$.

A contagem de bactérias aeróbias mesófilas foi realizada utilizando as diluições de $10^{-1}, 10^{-2} \mathrm{e}$ 
$10^{-3}$. Para a pesquisa de Coliformes Totais $\left(30^{\circ} \mathrm{C}\right)$

e Termotolerantes, as amostras foram diluídas até $10^{-2}$, inoculadas em tubos múltiplos contendo Caldo Lauril Sulfato Triptose e incubados em estufa de $36^{\circ} \mathrm{C} \pm 1$ por $48 \mathrm{hs}$, em seguida os tubos que deram leitura positiva foram repicados em tubos de Caldo Verde Brilhante Bile Lactose $2 \%$ a $36^{\circ} \mathrm{C} \pm 1$ e Caldo EC a $45^{\circ} \mathrm{C} \pm 1$, para a pesquisa de coliformes a $30^{\circ}$ e termotolerantes, respectivamente, durante 48 horas.

\section{Resultados e Discussões}

Das 104 amostras de leite pasteurizado analisadas no ano de 2008, 6 (5,8\%) apresentaram contaminação superior a $80.000 \mathrm{UFC} / \mathrm{mL}$ para contagem de aeróbios mesófilos. Das 269 amostras analisadas em 2011, 15 (5,6\%) apresentaram-se fora do padrão (tabela1). Já no ano de 2014, 84 amostras de leite pasteurizado foram analisadas, sendo que até o mês de junho, $22(26,2 \%)$ apresentaram-se fora do padrão.

Tabela 1 - Contagem de aeróbios mesófilos em amostras de leite pasteurizado, analisadas nos anos de 2008, 2011 e primeiro semestre de 2014, no norte do Paraná.

\begin{tabular}{|c|c|c|c|c|c|c|c|c|}
\hline \multirow{2}{*}{$\begin{array}{l}\text { Faixa de contagem } \\
(\mathrm{UFC} / \mathrm{mL})\end{array}$} & \multicolumn{2}{|c|}{2008} & \multicolumn{2}{|c|}{2011} & \multicolumn{2}{|c|}{2014} & \multicolumn{2}{|c|}{ Total } \\
\hline & $\mathrm{N}$ & $\%$ & $\mathrm{~N}$ & $\%$ & $\mathrm{~N}$ & $\%$ & $\mathrm{~N}$ & $\%$ \\
\hline$<100$ & 0 & 0.0 & 1 & 0.4 & 0 & 0.0 & 1 & 0.2 \\
\hline$[100 ; 1.000)$ & 29 & 27.9 & 38 & 14.1 & 2 & 2.4 & 69 & 15.1 \\
\hline$[1.000 ; 10.000)$ & 53 & 51.0 & 129 & 48.0 & 15 & 17.9 & 197 & 43.1 \\
\hline$[10.000 ; 80.000)$ & 16 & 15.4 & 86 & 32.0 & 45 & 53.6 & 147 & 32.2 \\
\hline$[80.000 ; 250.000)$ & 3 & 2.9 & 12 & 4.5 & 12 & 14.3 & 27 & 5.9 \\
\hline$>250.000$ & 3 & 2.9 & 3 & 1.1 & 10 & 11.9 & 16 & 3.5 \\
\hline Total & 104 & 100 & 269 & 100 & 84 & 100 & 457 & 100.0 \\
\hline
\end{tabular}

Fonte: $\mathrm{O}$ autor.

Houve um significativo aumento na contagem total de aeróbios mesófilos com o decorrer do tempo. Podemos perceber que com a substituição da IN 51, pela atual IN62, esperava-se uma redução na contagem desses micro-organismos, devido aos parâmetros microbiológicos mais severos para matéria prima. No entanto observou-se um aumento, não correspondendo às expectativas trazidas pela nova Instrução Normativa em vigor. Até 2011 cerca de 5,6\% das amostras apresentavam contagens de $80.000 \mathrm{UFC} / \mathrm{mL}$. Em 2014 este número aumentou para $26,2 \%$. Esses resultados indicam processamento inadequado e/ou recontaminação pós-pasteurização.
Giombelli et al. (2011), entre os anos de 2006 e 2008, no estado do Paraná, encontraram 29 $(23,77 \%)$ das 122 amostras de leite pasteurizado com contagens acima de $80.000 \mathrm{UFC} / \mathrm{mL}$.

O perfil de aeróbios mesofilos encontrados nessa pesquisa para o ano de 2014, assemelha-se ao obtido por Silva et al. (2008), que analisou 348 amostras de leite pasteurizado, oriundas do Programa do Leite, no estado de Alagoas, das quais 87 (25,0\%) estavam acima dos valores permitidos pela legislação.

Em relação aos coliformes a $30^{\circ}$, do total de 104 análises do ano de 2008, 18 (17,3\%) estavam acima do padrão da IN51, enquanto no ano de 2011, 39 (14,5\%), de 269 amostras, apresentaram- 
se acima do padrão (tabela 2). Observando-se um aumento nas contagens no ano de 2014 , onde 18 amostras $(21,4 \%)$, das 84 , encontraram-se fora do padrão estabelecido pela IN62, demonstrando uma oscilação da qualidade ao longo do tempo.

Em um trabalho semelhante, Tamanini et al. (2007), no estado do Paraná, encontraram 24 (30\%) das 80 amostras estudadas de leite Pasteurizado, fora do padrão $(\mathrm{NMP}=4 / \mathrm{mL})$ para coliformes à $30^{\circ} \mathrm{C}$. Silva et al. (2008) encontraram resultados ainda mais impactantes, $194(55,7 \%)$ de suas 348 amostras estavam acima do padrão para este grupo de micro-organismos.

Quantoàcontagem decoliformestermotolerantes, no ano de 2008, das 104 amostras apenas $1(1,0 \%)$ apresentou-se acima do padrão ( $\mathrm{NMP}=2 / \mathrm{mL})$, em 2011, 6 (2,2\%) das 269 amostras, e em 2014, 4 $(4,8 \%)$ amostras, de um total de 84 estavam acima do padrão, demonstrando um aumento no número de amostras fora do padrão (tabela 3).

Tabela 2 - Distribuição das Contagens de Coliformes à $30^{\circ} \mathrm{C}$ em amostras de leite pasteurizado, analisadas nos anos de 2008, 2011 e primeiro semestre de 2014, no norte do Paraná.

\begin{tabular}{c|cc|cc|cc|cc}
\hline \multirow{2}{*}{$\begin{array}{c}\text { Faixa de contagem } \\
(\mathrm{NMP} / \mathrm{mL})\end{array}$} & \multicolumn{2}{|c|}{2008} & \multicolumn{2}{c|}{2011} & \multicolumn{2}{c}{2014} & \multicolumn{2}{c}{ Total } \\
\cline { 2 - 10 } & $\mathrm{N}$ & $\%$ & $\mathrm{~N}$ & $\%$ & $\mathrm{~N}$ & $\%$ & $\mathrm{~N}$ & $\%$ \\
\hline$\leq 0,3$ & 58 & 55.8 & 168 & 62.5 & 41 & 48.8 & 267 & 58.4 \\
$(0,3 ; 2]$ & 25 & 24.0 & 45 & 16.7 & 19 & 22.6 & 89 & 19.5 \\
$(2 ; 4]$ & 3 & 2.9 & 17 & 6.3 & 6 & 7.1 & 26 & 5.7 \\
$>4$ & 18 & 17.3 & 39 & 14.5 & 18 & 21.4 & 75 & 16.4 \\
\hline Total & 104 & 100 & 269 & 100 & 84 & 100 & 457 & 100.0 \\
\hline
\end{tabular}

Fonte: $\mathrm{O}$ autor.

Tabela 3 - Distribuição das Contagens de Coliformes Termotolerantes em amostras de leite pasteurizado, analisadas nos anos de 2008, 2011 e primeiro semestre de 2014, provenientes de 18 laticínios no norte do Paraná.

\begin{tabular}{c|cc|cc|cc|cc}
\hline \multirow{2}{*}{$\begin{array}{c}\text { Faixa de contagem } \\
\text { (NMP/mL) }\end{array}$} & \multicolumn{2}{|c|}{2008} & \multicolumn{2}{|c|}{2011} & \multicolumn{2}{|c}{2014} & \multicolumn{2}{c}{ Total } \\
\cline { 2 - 10 } & $\mathrm{N}$ & $\%$ & $\mathrm{~N}$ & $\%$ & $\mathrm{~N}$ & $\%$ & $\mathrm{~N}$ & $\%$ \\
\hline$\leq 0,3$ & 98 & 94.2 & 246 & 91.4 & 73 & 86.9 & 417 & 91.2 \\
$(0,3 ; 2]$ & 5 & 4.8 & 17 & 6.3 & 7 & 8.3 & 29 & 6.3 \\
$(2 ; 4]$ & 0 & 0.0 & 2 & 0.7 & 0 & 0.0 & 2 & 0.4 \\
$>4$ & 1 & 1.0 & 4 & 1.5 & 4 & 4.8 & 9 & 2.0 \\
\hline Total & 104 & 100 & 269 & 100 & 84 & 100 & 457 & 100.0 \\
\hline
\end{tabular}

Fonte: $\mathrm{O}$ autor. 
Zocche et al. (2002) obteve excelente resultado em sua pesquisa realizada no oeste do Paraná, onde 100\% das 40 amostras se mantiveram dentro do padrão para coliformes termotolerantes. Já no estado de Minas Gerais, Santiago et al. (2011), em um experimento semelhante encontrou $22,3 \%$ de suas 18 amostras fora dos padrões estabelecidos, sendo um resultado bastante expressivo. Embora os resultados variem entre os pesquisadores, fica bem demonstrada a existência de problemas com a qualidade nos diferentes Estados do país.

Com relação as enzimas fosfatase alcalina e peroxidase, em todas as amostras analisadas verificamos que a fosfatase estava ausente, indicando que a pasteurização foi eficiente. Tamanini et al. (2007), na mesma região, estudando 80 amostras de leite pasteurizado, também verificou ausência de fosfatase em todas as amostras, indicando que a temperatura de pasteurização foi atingida. Durante os anos de 2008, 2011 e 2014 a temperatura de pasteurização foi respeitada, indicando eficiência do processo. No entanto, parte dos leites produzidos sofrem recontaminação após a pasteurização.

Dentre as 18 amostras analisadas por Santiago et al. (2011), no município de Diamantina-MG, 38,88\% (7 amostras) apresentaram resultados positivos para fosfatase alcalina.

A peroxidase estava ausente em 1 (1,0\%), 6(2,2\%) e 0 amostras, nos anos de 2008, 2011 e primeiro semestre de 2014, respectivamente, isso indica uma diminuição da prática de superaquecimento no último ano. Leites com baixa qualidade microbiológica são superaquecidos para garantir a durabilidade e os parâmetros microbiológicos até a validade. Essas amostras superaquecidas apresentariam contagens superiores às verificadas se as temperaturas de pasteurização fossem respeitadas.

Giombelli et al. (2011) encontraram 18 (9,38\%) das 122 amostras estudadas superaquecidas, enquanto Tamanini et al. (2007), analisando leite pasteurizado no norte do Paraná, encontrou 13 (16,2\%) de amostras com ausência de peroxidase. Zocche et al. (2002) não encontrou a presença dessa enzima em 50,0\% das amostras. Valbuena et al. (2004), analisando 216 amostras de leite pasteurizado na cidade de Maracaibo Venezuela, encontrou 99\% das amostras negativas para peroxidase, indicando um marcado superaquecimento no processamento térmico, possivelmente porque a matéria prima apresenta uma alta carga bacteriana. Os resultados dos estudos dos diversos autores demonstram que a prática do superaquecimento ocorre com frequência.

Sobre o índice crioscópico observamos que, no ano de 2008, das 104 amostras, 9 (8,7\%) encontraram-se fora dos padrões, sendo que 5 dessas ultrapassaram o limite máximo, que é $-0,530^{\circ} \mathrm{H}$, indicando adição de água ao leite. No ano de 2011, 12 (4,5\%), das 269 amostras se mostraram fora do padrão, sendo que 11 $(4,1 \%)$ delas também ultrapassaram o limite máximo permitido, e uma no ano de 2014 (1,2\%), das 84 analisadas. Os resultados indicam que fraude por adição de água tornou-se menos frequente ou mais sofisticada, dificultando a sua detecção. Silva et al. (2008) em Alagoas, encontraram dentre 348 amostras de leite pasteurizado, $89(25,6 \%)$ fora do padrão para o índice crioscópico. Esses resultados mostram que há uma grande falta de compromisso por parte da indústria, pois além de não garantir a qualidade de sua matéria-prima quanto à contaminação, a fraude é evidente, mostrando ineficiência no controle de qualidade para recepção de leite cru ou co-responsabilidade na fraude (figura 1).

Figura 1 - Comparação de resultados fora do padrão de Aeróbios Mesófilos, Coliformes $30^{\circ} \mathrm{C}$, Coliformes Termotolerantes, Peroxidase e Crioscopia nos anos de 2008, 2011 e primeiro semestre de 2014 analisados no Norte do Paraná.

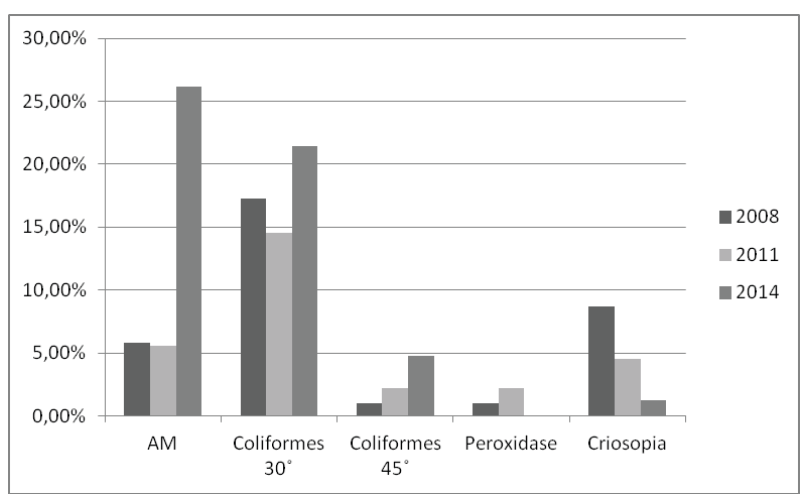

Fonte: $\mathrm{O}$ autor. 
Embora os parâmetros microbiológicos e físicoquímicos para leite pasteurizado não tenham sido alterados pelas sucessivas legislações, os parâmetros microbiológicos para leite cru tornaram-se muito mais severos. Na região Sul, Sudeste e Centrooeste os parâmetros diminuíram de 1.000.000UFC de aeróbios mesofilos por $\mathrm{mL}$ de leite (até julho de 2008) para 750.000UFC/mL (até julho de 2011), e para 600.000UFC/mL (até julho de 2014). Esperavase uma repercussão dos novos parâmetros no leite pasteurizado, o que não aconteceu.

A qualidade microbiológica do leite cru é influenciada fortemente pela higiene de ordenha. Praticas simples e baratas são capazes de diminuir significativamente a contaminação por microorganismos. A melhoria da qualidade é imediata após a implantação de práticas de higiene na ordenha. Assim atingir os parâmetros legais depende de convencimento dos produtores ou incentivos financeiros, como o pagamento por qualidade.

\section{Conclusão}

Avaliando os resultados no decorrer dos anos estudados, observa-se que a qualidade microbiológica diminuiu para todas as classes de micro-organismos.

Todas as amostras atingiram a temperatura de pasteurização e algumas foram superaquecidas, indicando problemas com a matéria prima e também com os procedimentos no beneficiamento industrial. Ainda parte das amostras sofre contaminação pós-pasteurização, o que pode comprometer sua segurança microbiológica.

Esses resultados indicam que ao longo dos anos a qualidade do leite não obteve melhora na região norte do Paraná, indo ao revés do que se esperava. Há necessidade da implantação de prática de higiene na ordenha, bem como de refrigeração eficiente do leite. Incentivos como pagamento por qualidade podem acelerar sobremaneira a adequação do leite aos parâmetros legais.
Ainda são necessários muitos esforços para melhorar a qualidade no setor lácteo, entretanto a conscientização do produtor com relação às boas práticas de higiene de ordenha e limpeza já são suficientes para adequar a legislação.

\section{Agradecimentos}

Ao laboratório de Inspeção de Produtos de Origem Animal (LIPOA), ao Centro Mesorregional de Excelência em Tecnologia do Leite do Norte Central, e à toda equipe do laboratório pelo auxílio na realização deste trabalho.

\section{Referencias}

BRASIL. Ministério da Agricultura, Pecuária e Abastecimento. Instrução Normativa $n^{\circ} 62$ de 29 de dezembro de 2011. Regulamento Técnico de Produção, Identidade e Qualidade do Leite tipo A, o Regulamento Técnico de Identidade e Qualidade de Leite Cru Refrigerado, o Regulamento Técnico de Identidade e Qualidade de Leite Pasteurizado e o Regulamento Técnico da Coleta de Leite Cru Refrigerado e seu Transporte a Granel. Diário Oficial da União, Brasília, 30 dez. 2011. Seção 1.

BRASIL. Ministério da Agricultura, Pecuária e Abastecimento. Instrução Normativa $n^{\circ} 68$ de 12 de dezembro de 2006. Métodos Analíticos Oficiais FísicoQuímicos, para Controle de Leite e Produtos Lácteos. Diário Oficial da União, Brasília, 14 dez. 2006. Seção 1, p. 8.

BRASIL. Ministério da Agricultura, Pecuária e Abastecimento. Instrução Normativa $n^{\circ} 62$ de 26 de agosto de 2003. Métodos Analíticos Oficiais para Análises Microbiológicas para Controle de Produtos de Origem Animal e Água. Diário Oficial da União, Brasília, 18 dez. 2003. Seção 1, p. 14.

BRASIL. Ministério da Agricultura, Pecuária e Abastecimento. Instrução Normativa $n^{\circ} 51$ de 18 de setembro de 2002. Regulamento Técnico de Produção, Identidade e Qualidade do Leite tipo A, do Leite tipo B, do Leite tipo C, do Leite Pasteurizado e do Leite Cru Refrigerado e o Regulamento Técnico da Coleta de Leite Cru Refrigerado e seu Transporte a Granel. Diário Oficial da União, Brasília, 20 set. 2002. Seção 1, p. 13. 
CUNHA, F. L. Avaliação da qualidade microbiológica, físico-química e contagem de células somáticas em leite de cabra produzido na região de Nova Friburgo-RJ. Dissertação (Mestrado em Medicina Veterinária) - Universidade Federal Fluminense, Niterói, 2007.

FLORIÃO, M. M. Boas práticas em bovinocultura leiteira com ênfase em sanidade preventiva. Niterói: Programa Rio Rural, 2013.

FRANCO,B.D. G.; LANDGRAF, M. Microbiologia dos alimentos. Rio de Janeiro: Atheneu, 2008.

GIOMBELLI, C. J.; TAMANINI, R.; BATAGLINI, A. P. P.; MAGNANI, D. F.; ÂNGELA, H. L.; BELOTI, V. Avaliação da qualidade microbiológica, físico-química dos parâmetros enzimáticos de leite pasteurizado e leite tipo B, produzidos no Paraná. Semina: Ciências Agrárias, Londrina. v. 32, n. 4. p. 1539-1546, 2011.

KOEHLER, J. C. Caracterização da bovinocultura de leite no Estado do Paraná. Curitiba: Secretaria de Estado da Agricultura e do Abastecimento - SEAB, 2000. Disponível em: <http://www.agricultura. pr.gov.br/arquivos/File/deral/cultura3.pdf $>$. Acesso em: 2 jul. 2014.

SANTIAGO, B. T.; PIRES, C. V.; COSTA SOBRINHO, P. S.; SANTOS, A. L.; SANTOS, J. M. Avaliação físico-química, microbiológica e de contagem de células somáticas de leites pasteurizados comercializados no município de Diamantina-MG. Alimentos e Nutrição, Araraquara, v. 22, n. 1, p. 39-44, jan./mar. 2011.

SILVA, M. C. D.; SILVA, J. V. L.; RAMOS, A. C. S.; MELO, R. O.; OLIVEIRA J. O. Caracterização microbiológica e físico-química de leite pasteurizado destinado ao programa do leite no Estado de Alagoas. Ciência e Tecnologia dos Alimentos, Campinas, v. 28, n. 1, jan./mar. 2008.

TAMANINI, R.; SILVA, L.C.C.; MONTEIRO, A. A.; MAGNANI, D.F.; BARROS, M.A.F.; BELOTI, V. Avaliação da qualidade microbiológica e dos parâmetros enzimáticos da pasteurização de leite tipo "C" produzido na região norte do Paraná. Semina: Ciências Agrárias, Londrina, v. 28, n. 3, p. 449-454, jul./set. 2007.
VALBUENA, E.; CASTRO, G.; LIMA, K.; ACOSTA, W.; BRIÑEZ, W.; TOVAR, A. Calidad microbiológica de las principales marcas de leche pasteurizada distribuidas en la ciudad de Maracaibo, Venezuela. Revista Cientifica FCV-LUZ, Maracaibo, v. 15, n. 1, p. 59-67, 2004.

VOLPI, R.; DIGIOVANI, M. S. C. Aspectos econômicos da produção e dados estatísticos. Boletim Informativo, Curitiba, n. 997, mar. 2008. Disponível em: <http:/www.faep.com.br/boletim/ bi997/encarte/encbi997pag02.htm>. Acesso em: 6 mar. 2013.

ZOCCHE, F.; BESSOT, L. S.; VARCELLOS, V. C.; PARANHOS, J. K.; ROSA, S. T. M.; RAYMUNDO, N. K. Qualidade microbiológica e físico-química do leite pasteurizado produzido na região oeste do Paraná. Archives of Veterinary Science, Curitiba, v. 7, n. 2, p. 59-67, 2002. 